\title{
Bacterial Pathogens and Antimicrobial Resistance Patterns in Pediatric Urinary Tract Infections: A Four-Year Surveillance Study (2009-2012)
}

\author{
Seyed Reza Mirsoleymani, ${ }^{1}$ Morteza Salimi, ${ }^{2}$ Masoud Shareghi Brojeni, ${ }^{3}$ \\ Masoud Ranjbar, ${ }^{3}$ and Mojtaba Mehtarpoor ${ }^{4}$ \\ ${ }^{1}$ Department of Nursing, Faculty of Nursing and Midwifery, Shahid Beheshti University of Medical Sciences, \\ Tehran 1985717443, Iran \\ ${ }^{2}$ Department of Physiology, Faculty of Medicine, Shahid Beheshti University of Medical Sciences, Tehran 1985717443, Iran \\ ${ }^{3}$ Student Research Committee, Hormozgan University of Medical Sciences, Bandar Abbas 7914964153, Iran \\ ${ }^{4}$ Department of Health Management and Economics, School of Public Health, Tehran University of Medical Sciences, \\ Tehran 1417614411, Iran
}

Correspondence should be addressed to Masoud Ranjbar; masoudranjbar857@gmail.com

Received 4 December 2013; Revised 15 April 2014; Accepted 30 April 2014; Published 19 May 2014

Academic Editor: Hans Juergen Laws

Copyright (C) 2014 Seyed Reza Mirsoleymani et al. This is an open access article distributed under the Creative Commons Attribution License, which permits unrestricted use, distribution, and reproduction in any medium, provided the original work is properly cited.

\begin{abstract}
The aims of this study were to assess the common bacterial microorganisms causing UTI and their antimicrobial resistance patterns in Bandar Abbas (Southern Iran) during a four-year period. In this retrospective study, samples with a colony count of $\geq 10^{5} \mathrm{CFU} / \mathrm{mL}$ bacteria were considered positive; for these samples, the bacteria were identified, and the profile of antibiotic susceptibility was characterized. From the 19223 samples analyzed, 1513 (7.87\%) were positive for bacterial infection. UTI was more frequent in male (54.9\%). E. coli was reported the most common etiological agent of UTI (65.2\%), followed by Klebsiella spp. (26\%), Pseudomonas aeruginosa (3.6\%), and Staphylococcus coagulase positive (3.7\%). Results of antimicrobial susceptibility analysis for E. coli to commonly used antibiotics are as follows: Amikacin (79.7\%), Ofloxacin (78.3\%), Gentamicin (71.6\%), Ceftriaxone (41.8), Cefotaxime (41.4\%), and Cefixime (27.8\%). Empirical antibiotic selection should be based on awareness of the local prevalence of bacterial organisms and antibiotic sensitivities rather than on universal or even national guidelines. In this study, Amikacin and Gentamicin were shown to be the most appropriate antibiotics for empiric therapy of pyelonephritis, but empirical therapy should only be done by specialist physicians in cases where it is necessary while considering sex and age of children.
\end{abstract}

\section{Introduction}

Urinary tract infection (UTI) is a common health problem during the childhood period and it is an important cause of morbidity and mortality in the first 2 years of life [1-4]. The reported incidence of UTI is $7 \%$ among girls and $2 \%$ among boys during the first 6 years of life [5]. The main objects in childhood urinary tract infections are rapid recovery from complaints and prevention of related complications, such as urosepsis, urolithiasis, and renal abscess, as well as the prevention of permanent renal parenchymal damage [6]. To achieve these aims, empirical antibiotic prescription is often endorsed even before the culture results are available [7]. On the other hand, antibiotic resistance of urinary tract pathogens has been known to increase worldwide, especially to commonly used antimicrobials $[8,9]$. The increasing antibiotic resistance trends are likely to have important clinical implications for the empirical use of antibiotics [10]. For this reason, knowledge of the etiology pathogens of UTIs and their antimicrobial resistance patterns in specific geographical locations may aid clinicians in choosing the appropriate antimicrobial empirical treatment [11]. Prior to this study, the frequency of bacterial species causing UTI and their susceptibility patterns to most commonly used antibiotics has 
not been previously determined in the southern provinces of Iran; so the aim of this study was to characterize these factors in this region of Iran.

\section{Methods}

This retrospective study analyzed the bacteria isolated from patients with UTI at the Children's Hospital, the main center for newborns and children located in Bandar Abbas, capital of Hormozgan Province, South of Iran. Urine samples were obtained from outpatients and inpatients with suspected UTI and those who were admitted in pediatric wards with signs and symptoms of UTI to document the common bacterial species causing UTI and their antibacterial susceptibility profile. The period of study was from 2009 to 2012. Patients were children aged from 1 week to 16 years without history of genitourinary abnormalities, recent hospitalization, or antibiotic usage. Patients were hospitalized for evaluation and treatment with signs and symptoms of acute pyelonephritis, including: temperature $\geq 38^{\circ} \mathrm{C}$, chills, frequency, dysuria, urgency, suprapubic and/or flank tenderness, pyuria (defined as $\geq 5 \mathrm{WBC} / \mathrm{Hpf}$ ), and fever with unknown source in children and in neonates (7-30 days of age) with clinical evidences of sepsis.

Data on age, sex, result of urine culture, the etiological agent, and susceptibility pattern were obtained from the medical records of patients. Urine samples were collected using midstream method in toilet-trained children and using cleancatch methods or sterile bladder catheter in younger children and infants.

Samples were inoculated on blood agar and eosin methylene blue agar plates and then were read after overnight incubation at $37^{\circ} \mathrm{C}$. After incubation, the urine culture samples were classified as negative, positive, and contaminated. When polymorphic bacterial growth (two or more bacterial species growth in one plate) was observed, the samples were classified as contaminated (exclusion criteria). The urine cultures were considered as negative when bacterial growth was lower than $10^{3} \mathrm{CFU} / \mathrm{mL}$ (exclusion criteria). Growth of two or more bacterial species (polymorphic bacterial growth) was considered as an exclusion criterion. When monomorphic bacterial growth was higher than $10^{5} \mathrm{CFU} / \mathrm{mL}$, the culture was classified as positive (inclusion criteria) and, for these cases, the antimicrobial susceptibility test (AST) was performed. The AST was also performed when the result of urine culture was between $10^{4}$ and $10^{5} \mathrm{CFU} / \mathrm{mL}$. Identification of bacterial microorganisms was made on the basis of gram reaction, morphology and biochemical features. The AST was performed by Kirby-Bauer disk diffusion method. A bacterial suspension in physiological saline solution was prepared by picking up 1-2 colonies from pure cultures. The suspension was spread on Mueller-Hinton Agar plate by a swab. Antibiotic disks were placed onto the cultures medium surface. The culture plates were incubated at $37^{\circ} \mathrm{C}$ for 24 hours; then inhibition zones were measured and hereby the antimicrobial efficacy was determined [12]. The commercial antibiotics used for isolates included Ciprofloxacin,
Trimethoprim-sulfamethoxazole (Cotrimoxazole), Gentamicin, Tobramycin, Ampicillin, Nitrofurantoin, Nalidixic acid, Ceftriaxone, Cefotaxime, Cefalexin, Cefazolin, Amoxicillin, Oxacillin, Cefixime, Ceftazidime, Erythromycin, Tetracycline, Clindamycin, Ofloxacin, and Amikacin; in addition to these antibiotics, Penicillin and Erythromycin were used for gram positive bacteria. The data were analyzed using the Statistical Package for the Social Sciences (SPSS) 16.0 for Windows. The normality of data and homogeneity of variance were checked before analysis. As most of the variables failed, these statistical method assumptions and the nonparametric Kruskal-Wallis test, as well as chi square test, were used.

\section{Results}

From January 2009 to 2012, a total of 19223 urine samples were submitted for analysis and culture. These samples showed 1513 (7.87\%; 95\% CI 7.49-8.2\%) bacterial growth higher than $10^{5} \mathrm{CFU} / \mathrm{mL}$. The prevalence of UTI among male and female children suspected to have UTI was $5.1 \%$ (845/16282; 95\% CI 4.78-5.43\%) and 22.4\% (659/2941; 95\% CI 20.9-23.9\%), respectively. Only the first urine sample of one patient and monomorphic bacterial growth samples was considered in this study. 176 of these samples were Staphylococcus coagulase negative (rather a contamination microorganism) and were excluded from the study. So, finally, 1209 samples were included. 664 (54.9\%) of these patients were males and 545 (45.1\%) were females. Of these patients, 437 (36.1\%), 377 (31.2\%), and $395(32.7 \%)$ were neonates (<28 days), infants (28 days to 1 years), and children (1 years to 14 year), respectively. The predominant agents of UTI were successively $E$. coli (65.2\%; 95\% CI 62.5-67.8\%), Klebsiella spp. (26\%; 95\% CI 23.6-28.4\%), Pseudomonas aeruginosa (3.6\%; 95\% CI 2.6$4.6 \%)$, Staphylococcus coagulase positive (3.7\%; 95\% CI 2.7$4.7 \%)$, Citrobacter $(0.9 \%$; 95\% CI 0.4-1.3\%), Enterobacter spp. (0.4\%; 95\% CI 0.1-0.7\%), and Proteus mirabilis (0.2\%; 95\% CI $0.0-0.4 \%$ ) (Table 1).

Analysis of the results according to patient gender represented that, although $E$. coli is the predominant isolated pathogen from both sexes, it occurred more frequently in females $(70.8 \%$ in females compared to $60.5 \%$ in males: significant at $\rho=0.001$ (chi square $=11.359)$ ), whereas the prevalence of UTI due to Klebsiella spp. was higher in males than in females $(28.3 \%$ in males compared to $23.1 \%$ in females, respectively. Significant at $\rho=0.001$ (chi square $=$ 11.359)). And the prevalence of UTI caused by Pseudomonas aeruginosa was significantly higher in males at $\rho=0.035$ (chi square $=4.45$ ).

Table 1 illustrates incidence of the main bacterial pathogens implicated in urinary tract infection, according sex and age during the study period. Significant (Kruskal-Wallis test, $\rho<0.05$ ) changes in the main bacterial pathogens responsible for UTI were observed during the study period. In general, the incidence of Staphylococcus coagulase positive increased and the incidence of Klebsiella spp. decreased during the period of the study (Figure 1).

In vitro sensitivity testing showed that the mean susceptibility E. coli had a sensitivity rate of $79.7 \%$ to Amikacin and 
TABLE 1: The main bacterial pathogens implicated in urinary tract infection by sex and age throughout the study period.

\begin{tabular}{|c|c|c|c|c|c|c|c|c|c|}
\hline \multirow{2}{*}{ Bacteria } & \multicolumn{3}{|c|}{ Neonates } & \multicolumn{3}{|c|}{ Infants } & \multicolumn{3}{|c|}{ Children } \\
\hline & $\begin{array}{c}\text { Total }^{\mathrm{a}} \\
(N=437)\end{array}$ & $\begin{array}{c}\text { Male }^{\mathrm{b}} \\
(n=260)\end{array}$ & $\begin{array}{l}\text { Female }^{\mathrm{b}} \\
(n=177)\end{array}$ & $\begin{array}{c}\text { Total }^{\mathrm{a}} \\
(N=377)\end{array}$ & $\begin{array}{c}\text { Male }^{\mathrm{b}} \\
(n=217)\end{array}$ & $\begin{array}{l}\text { Female }^{\mathrm{b}} \\
(n=160)\end{array}$ & $\begin{array}{c}\text { Total }^{\mathrm{a}} \\
(N=395)\end{array}$ & $\begin{array}{c}\text { Male }^{\mathrm{b}} \\
(n=187)\end{array}$ & $\begin{array}{l}\text { Female }^{\mathrm{b}} \\
(n=208)\end{array}$ \\
\hline E. coli & 57.7 & 54.2 & 62.7 & 70.8 & 66.8 & 76.3 & 68.1 & 62.0 & 73.6 \\
\hline Klebsiella & 36.2 & 38.1 & 33.3 & 19.4 & 21.2 & 16.8 & 21 & 23.0 & 19.2 \\
\hline $\begin{array}{l}\text { P. aerugi- } \\
\text { nosa }\end{array}$ & 2.3 & 3.1 & 1.1 & 5.0 & 6.0 & 3.8 & 3.8 & 5.3 & 2.4 \\
\hline $\begin{array}{l}\text { S. coagulase } \\
\text { positive }\end{array}$ & 1.6 & 2.3 & 0.6 & 3.2 & 4.1 & 1.8 & 6.6 & 9.2 & 4.3 \\
\hline Citrobacter & 1.6 & 1.5 & 1.7 & 0.8 & 0.5 & 1.3 & 0.3 & 0.0 & 0.5 \\
\hline Enterobacter & 0.6 & 0.8 & 0.6 & 0.5 & 0.9 & 0.0 & 0.0 & 0.0 & 0.0 \\
\hline Proteus & 0.0 & 0.0 & 0.0 & 0.3 & 0.5 & 0.0 & 0.3 & 0.5 & 0.0 \\
\hline
\end{tabular}

${ }^{a}$ Percentage determined in relation to $N$; ${ }^{\text {b }}$ percentage determined in relation to $n$.

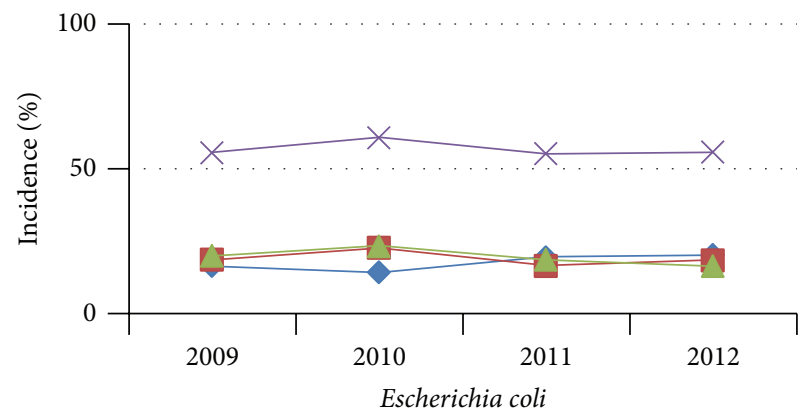

(a)

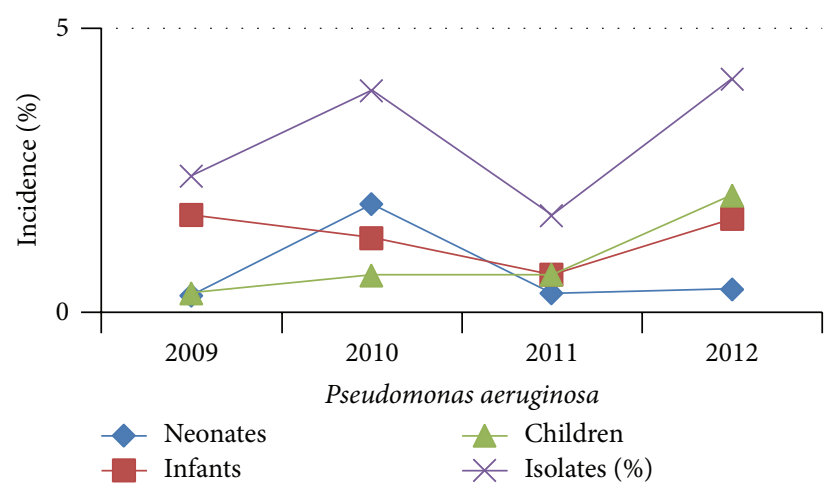

(c)

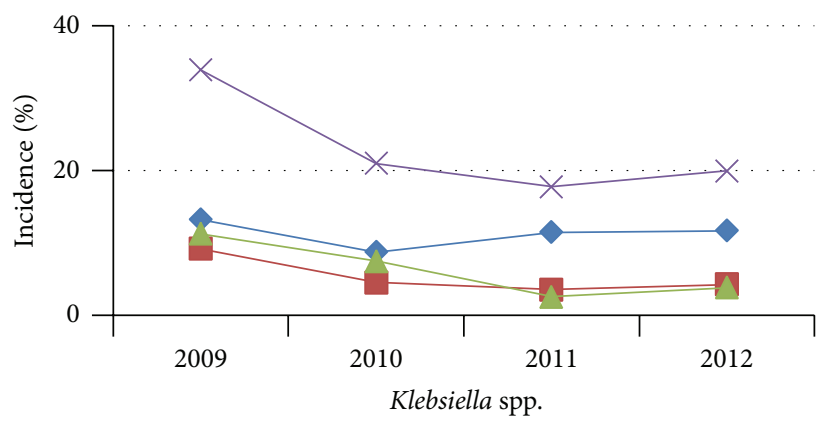

(b)

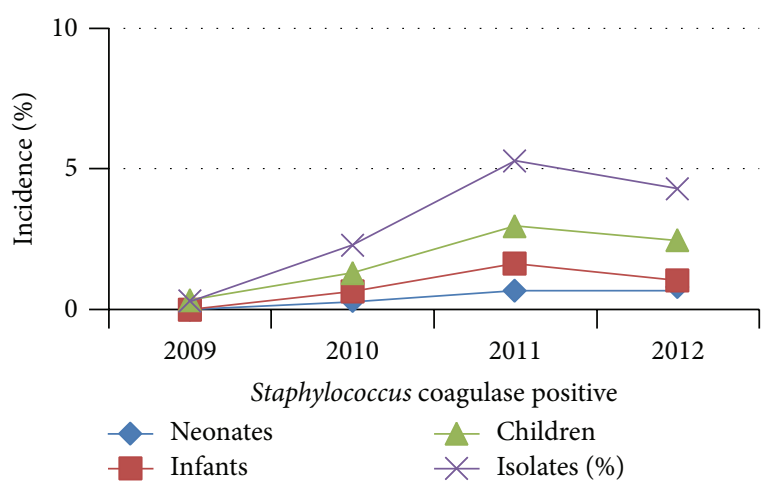

(d)

FIGURE 1: Incidence of the main bacteria implicated in UTI by age during the study period.

77.1\% to Ciprofloxacin. In this study, the highest resistance rate of this germ was to Ampicillin (83.5\%) followed by Trimethoprim-sulfamethoxazole (75.4\%). The E. coli resistance to Trimethoprim-sulfamethoxazole (one of the most important UTI empirical therapy options) changed significantly over the study period (chi square test, $\rho<0.001$ ). In general, the resistance rate has been increased in females but has been reduced in males (Table 2). Klebsiella spp., the second common germ producing UTI, showed the highest sensitivity to Ciprofloxacin (81.3\%) and Amikacin $(73.1 \%)$ and the highest resistance to Ampicillin (86.3\%) and Cephalothin (62.4\%). Pseudomonas was $100 \%$ resistant to
Trimethoprim-sulfamethoxazole in this study. It showed the highest sensitivity to Tobramycin (100\%), Amikacin (86.4\%), and Gentamycin (84\%). The antibiotic resistance patterns of E. coli (the most common germ) and Pseudomonas aeruginosa (the most antibiotic resistant germ) agents of UTI are presented in Figures 2 and 3.

\section{Discussion}

Urinary tract infection (UTI) is of major clinical importance owing to considerably high morbidity and mortality rates among children [3]. In this study, of 19223 patients who were 


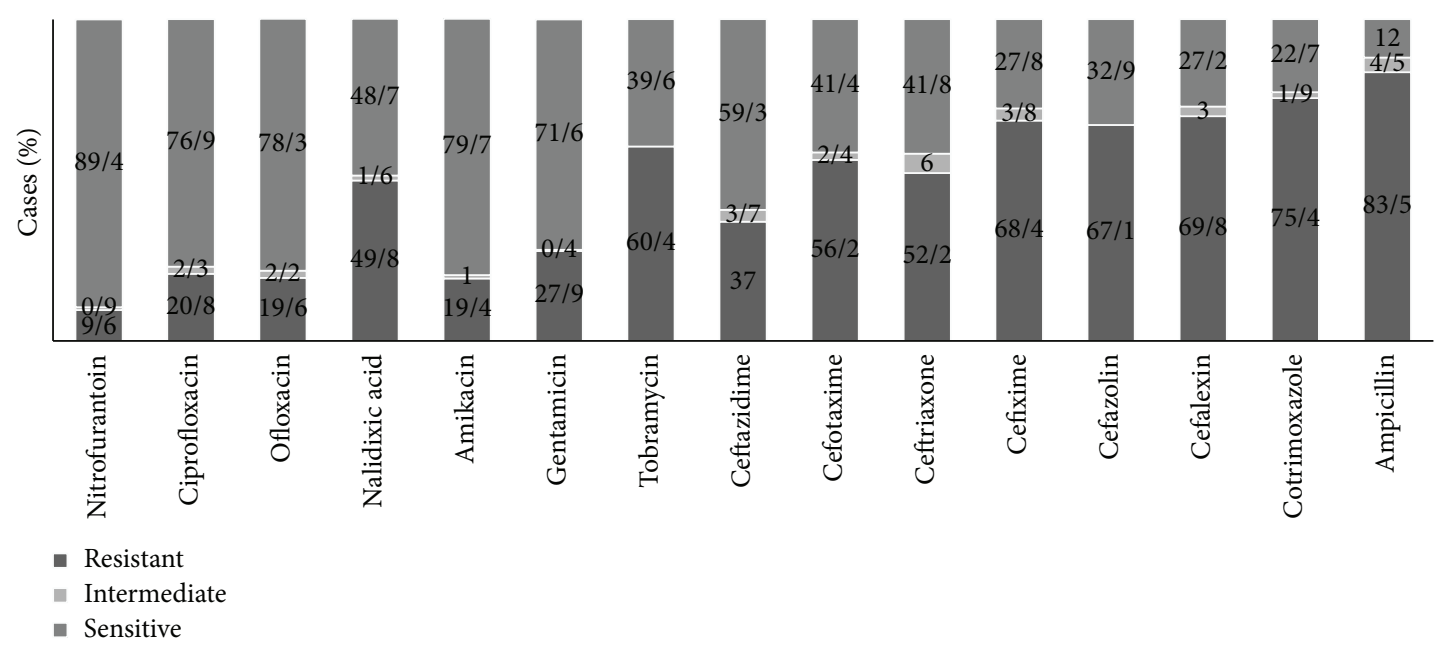

FIGURE 2: E. coli sensitivity and resistance pattern of bacteria causing UTI to antibiotics.

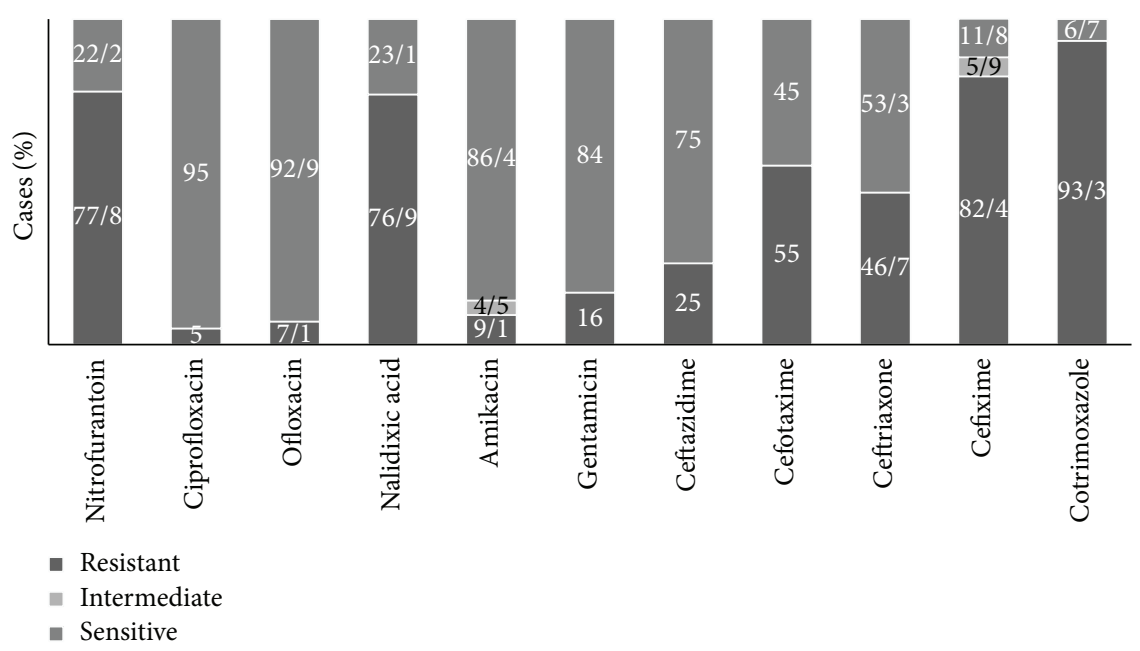

FIgURE 3: Pseudomonas aeruginosa sensitivity and resistance pattern of bacteria causing UTI to antibiotics.

TABle 2: The E. coli resistance to Trimethoprim-sulfamethoxazole over the study period.

\begin{tabular}{lcccccc}
\hline & \multicolumn{6}{c}{ Year } \\
& 2009 & 2010 & 2011 & 2012 & $P$ value & chi square \\
\hline Male & $72.7 \%$ & $81.7 \%$ & $47.9 \%$ & $64.0 \%$ & $<0.001$ & 33.961 \\
Female & $68.4 \%$ & $72.3 \%$ & $66.7 \%$ & $86.9 \%$ & 0.004 & 19.201 \\
\hline Total & $70.6 \%$ & $77.6 \%$ & $56.6 \%$ & $73.5 \%$ & $<0.001$ & 40.589 \\
\hline
\end{tabular}

suspected to UTI and from whom urine samples were taken, only $7.87 \%$ had a urinary tract infection. Its relative ratio varies in different areas of Iran. In studies carried out in Tabriz and Qazvin, $13.2 \%$ and 7.2\% of pediatric suspected of urinary tract infection had a positive urine culture [10, 13] that was similar to our results. This is possibly because UTI symptoms are not a dependable indicator of infection and in children younger than 2 years of age are nonspecific [10] therefore, urine culture of suspected children is necessary for a definitive diagnosis of UTI.
In this study, E. coli, as the most common pathogen, incidence among females was significantly higher than in males and incidence of Klebsiella, as the second most common pathogen, was significantly higher in males. On the other hand, in this study, $70.5 \%$ of UTI caused by Pseudomonas aeruginosa were in males and only $29.5 \%$ were in females. Pseudomonas aeruginosa is an opportunistic uropathogen for community-acquired UTI [12] and also totally resistant to first line empirical antibiotics (special importance of this pathogen) [14]. Be male, received recent antibiotic therapy, have a neurogenic bladder and have a history of urinary tract procedures such as catheterization are known as risk factors for UTI caused by Pseudomonas aeruginosa [15]. So similar to other literature, sex might influence the etiology of UTI and most be considered in empirical therapy [12].

In this study, among children who have a positive urine culture, $55.9 \%$ were males and $44.1 \%$ were females. Also, most of the participants were infants and neonates $(65.2 \%)$ and $34.8 \%$ were children. Male children are infected more than girls during the first 3 months of their life but, incidence of 
UTI among girls who have more than one year old is much more [16] possibly because the structural anomalies incidence in first 3 months among boys is more. Boys were more at risk of wrong diagnosis of UTI than female children too. In this study, the frequencies of positive cultures were $5.1 \%$ for males and $22.4 \%$ for females (ratio 1: 4 ). Farajnia et al. reported this ratio $1: 2[10]$ and Farrell et al. reported this ratio $1: 4.1$ [17]. The cause of this needs more study.

Chi square test showed that pathogens differed significantly $(\rho<0.001)$ across the three age groups of study. $E$. coli prevalence was higher in infants (63.1\%), incidence of Klebsiella was higher in neonate (32.9\%), and Pseudomonas aeruginosa incidence was higher in infants, but the Staphylococcus coagulase positive prevalence was higher in children (5.4\%). So age might influence the etiology of urinary tract infection as has been shown in the study of Afsharpaiman et al. [16]. Overall, these results indicate that urine culture is necessary for a definitive diagnosis of UTI and that empirical therapy should only be done by specialist physicians in case where it is necessary while considering sex and age of children.

E. coli is the leading uropathogen and was isolated from $56.6-84.6 \%$ of Iranian children with febrile UTI $[16,18]$. The results of this study in this context are in agreement with previous literature findings. E. coli was the most causative organism responsible for $65.2 \%$ of urinary tract infections. But the resistance pattern of this germ to antibiotics was very different in comparison with other studies. For example Sharifian et al. reported the highest susceptibility percentage of E. coli to Ceftriaxone (97.8\%) and Cefotaxime (95.2\%) in 2006 in Tehran [19]. But, in this study, E. coli specimens were $52.2 \%$ and $56.2 \%$ resistant to Ceftriaxone and Cefotaxime, respectively, probably because the pattern of the sensitivity of microorganisms to antibiotics varies over time and between different geographical locations. There was no study before this study for physicians of this region to estimate the most common pathogen and its resistant pattern in pediatrics, but they empirically consider $E$. coli as the most causative agent and Ceftriaxone and Cefixime as the most appropriate choice for UTI treatment but the results of this study have shown that Ceftriaxone probably cannot be the best choice hereafter. On the other hand, according to the results of this study, E. coli specimens were $64.8 \%$ resistant to Cefixime and $75.4 \%$ resistant to Trimethoprimsulfamethoxazole. Although Cefixime probably cannot be the best choice, it is better than Trimethoprim-sulfamethoxazole for outpatient treatment option.

In a study conducted in Khartoum, Ali and Osman reported that the mean susceptibility of all isolates was too high to Gentamicin (96\%), Ciprofloxacin (94\%), and Ceftriaxone $(90 \%)$ whereas the lowest percentages of susceptibility were reported for Amoxicillin clavulanate (19\%) and Ampicillin (14\%) [20]. In a study conducted in the US hospitals, resistance among E. coli was highest for Trimethoprimsulfamethoxazole $(24 \%)$ but lower for Nitrofurantoin $(<1 \%)$ and Cephalothin (15\%) [5]. This study revealed a high E. coli resistance rate to antibiotics. Except for Nitrofurantoin and Ciprofloxacin that are not appropriate options for UTI treatment in children [19], the highest percentages of susceptibility were seen for Amikacin (79.7\%), Ofloxacin (78.3\%), and Gentamicin (71.6\%), whereas the highest percentages of resistance for this pathogen were found for Ampicillin (83.5\%), Cotrimoxazol (75.4\%), and Cefalexin (69.8\%). Other studies in Iran have also indicated a high resistance rate to antibiotics. For example, Farajnia et al. reported resistance rate of $90.7 \%$ to Ampicillin, $51.8 \%$ to Cotrimoxazol, and $26.5 \%$ to Cefalexin, whereas the highest percentages of susceptibility were seen for Amikacin (96.6\%) and Gentamicin (92.9\%) in 2008 in Tabriz [10]. These significantly higher bacterial resistance rates to antibiotics in our country in comparison with other countries seem to be the result of two factors: first, a higher rate of antibiotic usage by families even in the absence of a prescription and, second, a population with a high percentage of young individuals since UTI is more common in the early years of life (UTI is most common in girls aged 3 to 5 years) [19]. The other factor that probably caused this study to show higher bacterial resistant rates of antibiotic is the empirical therapy itself because the results of this study showed that only $7.87 \%$, of who were suspected to UTI, had a urinary tract infection in reality. Probably a high rate of antibiotics using resulted in various antibiotic resistance patterns in different parts of Iran.

In conclusion, we suggest that empirical antibiotic selection should be based on knowledge of the local prevalence of bacterial organisms and antibiotic sensitivities rather than on universal or even national guidelines. In this study, Amikacin and Gentamicin were shown to be the most appropriate antibiotics for empiric therapy of pyelonephritis, but, empirical therapy should only be done by specialist physicians in cases where it is necessary while considering sex and age of children.

\section{Conflict of Interests}

The authors declare that there is no conflict of interests regarding the publication of this paper.

\section{Acknowledgments}

The authors would like to hereby thank the Student Research Committee of Hormozgan University of Medical Sciences, Bandar Abbas, Iran, specially Ms. Soghra Fallahi and Mr. Mohammad Esmaeil Shahrzad for sharing their invaluable advice.

\section{References}

[1] L. P. Jadresić, "Diagnosis and management of urinary tract infections in children," Paediatrics and Child Health, vol. 20, no. 6, pp. 274-278, 2010.

[2] O. Adjei and C. Opoku, "Urinary tract infections in African infants," International Journal of Antimicrobial Agents, vol. 24, no. 1, pp. S32-S34, 2004.

[3] F. Mortazavi and N. Shahin, "Changing patterns in sensitivity of bacterial uropathogens to antibiotics in children," Pakistan Journal of Medical Sciences, vol. 25, no. 5, pp. 801-805, 2009. 
[4] S. Habib, "Highlights for management of a child with a urinary tract infection," International Journal of Pediatrics, vol. 2012, Article ID 43653, 6 pages, 2012.

[5] R. S. Edlin, D. J. Shapiro, A. L. Hersh, and H. L. Copp, "Antibiotic resistance patterns in outpatient pediatric urinary tract infections," The Journal of Urology, vol. 190, no. 1, pp. 222-227, 2013.

[6] R. Beetz and M. Westenfelder, "Antimicrobial therapy of urinary tract infections in children," International Journal of Antimicrobial Agents, vol. 38, pp. 42-50, 2011.

[7] F. E. Abdullah, A. A. Memon, M. Y. Bandukda, and M. Jamil, "Increasing ciprofloxacin resistance of isolates from infected urines of a cross-section of patients in Karachi," BMC Research Notes, vol. 5, no. 1, pp. 696-701, 2012.

[8] A. Alemu, F. Moges, Y. Shiferaw, K. Tafess, A. Kassu, B. Anagaw et al., "Bacterial profile and drug susceptibility pattern of urinary tract infection in pregnant women at University of Gondar Teaching Hospital, Northwest Ethiopia," BMC Research Notes, vol. 5, no. 1, pp. 197-204, 2012.

[9] G. Schmiemann, I. Gagyor, E. Hummers-Pradier, and J. Bleidorn, "Resistance profiles of urinary tract infections in general practice-an observational study," BMC Urology, vol. 12, no. 1, pp. 33-38, 2012.

[10] S. Farajnia, M. Y. Alikhani, R. Ghotaslou, B. Naghili, and A. Nakhlband, "Causative agents and antimicrobial susceptibilities of urinary tract infections in the northwest of Iran," International Journal of Infectious Diseases, vol. 13, no. 2, pp. 140-144, 2009.

[11] N. Kashef, G. E. Djavid, and S. Shahbazi, "Antimicrobial susceptibility patterns of community-acquired uropathogens in Tehran, Iran," Journal of Infection in Developing Countries, vol. 4, no. 4, pp. 202-206, 2010.

[12] I. Linhares, T. Raposo, A. Rodrigues, and A. Almeida, "Frequency and antimicrobial resistance patterns of bacteria implicated in community urinary tract infections: a ten-year surveillance study (2000-2009)," BMC Infectious Diseases, vol. 13, no. 1, article 19, 2013.

[13] F. Vaezzadeh and M. Sharifi-Yazdi, "Laboratory evaluation of urine culture and drug resistance in children clinically suspected of urinary tract infection (UTI)," Iranian Journal of Public Health, vol. 30, pp. 123-127, 2001.

[14] M. Bitsori, S. Maraki, S. Koukouraki, and E. Galanakis, "Pseudomonas aeruginosa urinary tract infection in children: Risk factors and outcomes," Journal of Urology, vol. 187, no. 1, pp. 260264, 2012.

[15] J. H. Tabibian, J. Gornbein, A. Heidari et al., "Uropathogens and host characteristics," Journal of Clinical Microbiology, vol. 46, no. 12, pp. 3980-3986, 2008.

[16] S. Afsharpaiman, F. Bairaghdar, M. Torkaman, Z. Kavehmanesh, S. Amirsalari, M. Moradi et al., "Bacterial pathogens and resistance patterns in children with community-acquired urinary tract infection: a cross sectional study," Journal of Comprehensive Pediatrics, vol. 3, no. 1, pp. 16-20, 2012.

[17] D. J. Farrell, I. Morrissey, D. de Rubeis, M. Robbins, and D. Felmingham, "A UK multicentre study of the antimicrobial susceptibility of bacterial pathogens causing urinary tract infection," Journal of Infection, vol. 46, no. 2, pp. 94-100, 2003.

[18] Y. Panahi, F. Beiraghdar, Y. Moharamzad, Z. K. Matinzadeh, and B. Einollahi, "The incidence of urinary tract infections in febrile children during a two-year period in Tehran, Iran," Tropical Doctor, vol. 38, no. 4, pp. 247-249, 2008.

[19] M. Sharifian, A. Karimi, S. R. Tabatabaei, and N. Anvaripour, "Microbial sensitivity pattern in urinary tract infections in children: a single center experience of 1,177 urine cultures," Japanese Journal of Infectious Diseases, vol. 59, no. 6, pp. 380382, 2006.

[20] E. Ali and A. Osman, "Acute urinary tract infections in children in Khartoum State: pathogens, antimicrobial susceptibility and associated risk factors," Arab Journal of Nephrology and Transplantation, vol. 2, no. 2, pp. 11-16, 2009. 


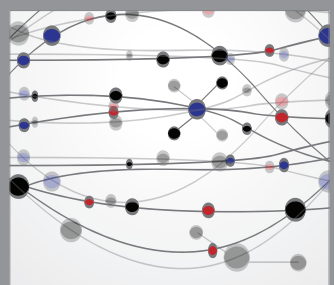

The Scientific World Journal
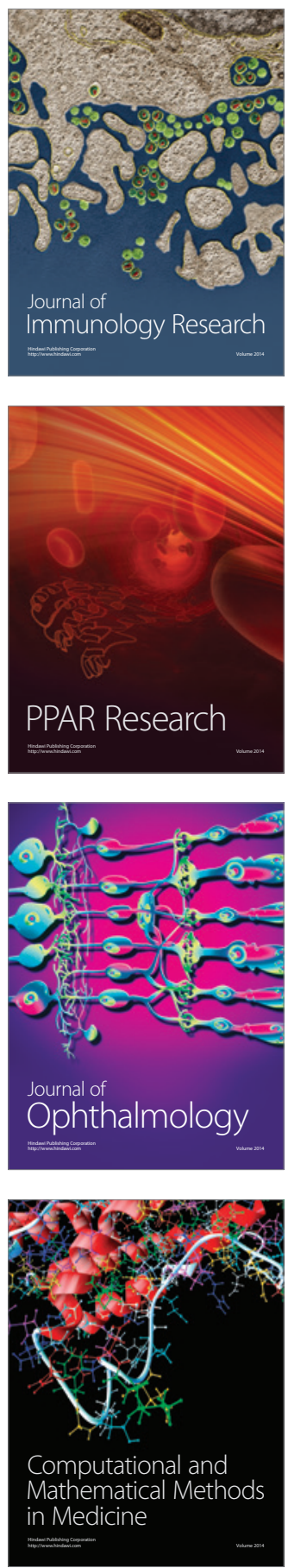

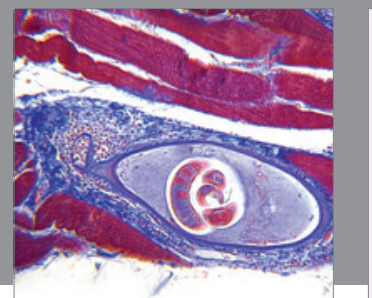

Gastroenterology

Research and Practice
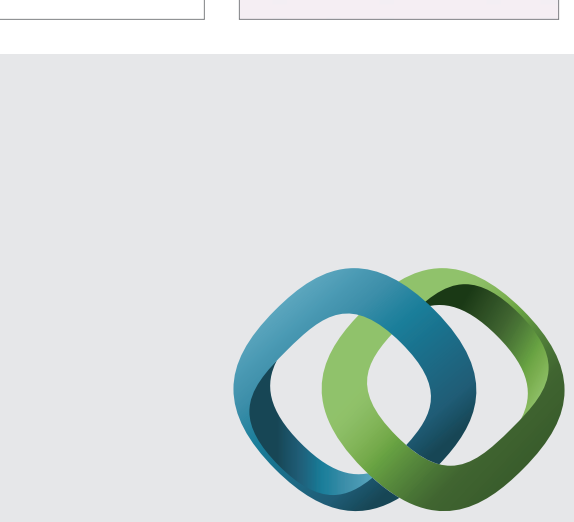

\section{Hindawi}

Submit your manuscripts at

http://www.hindawi.com
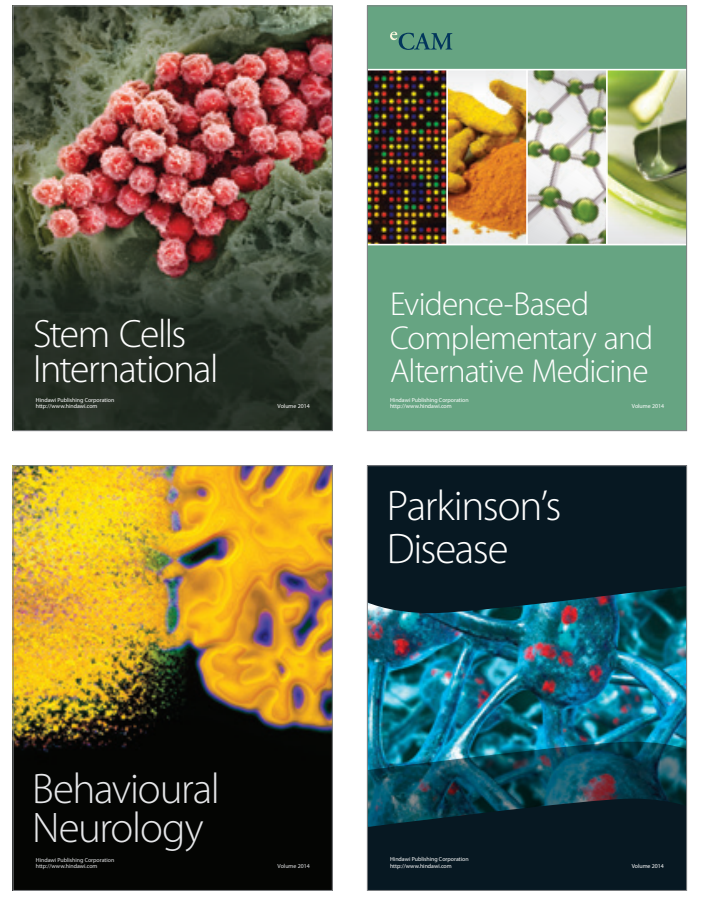
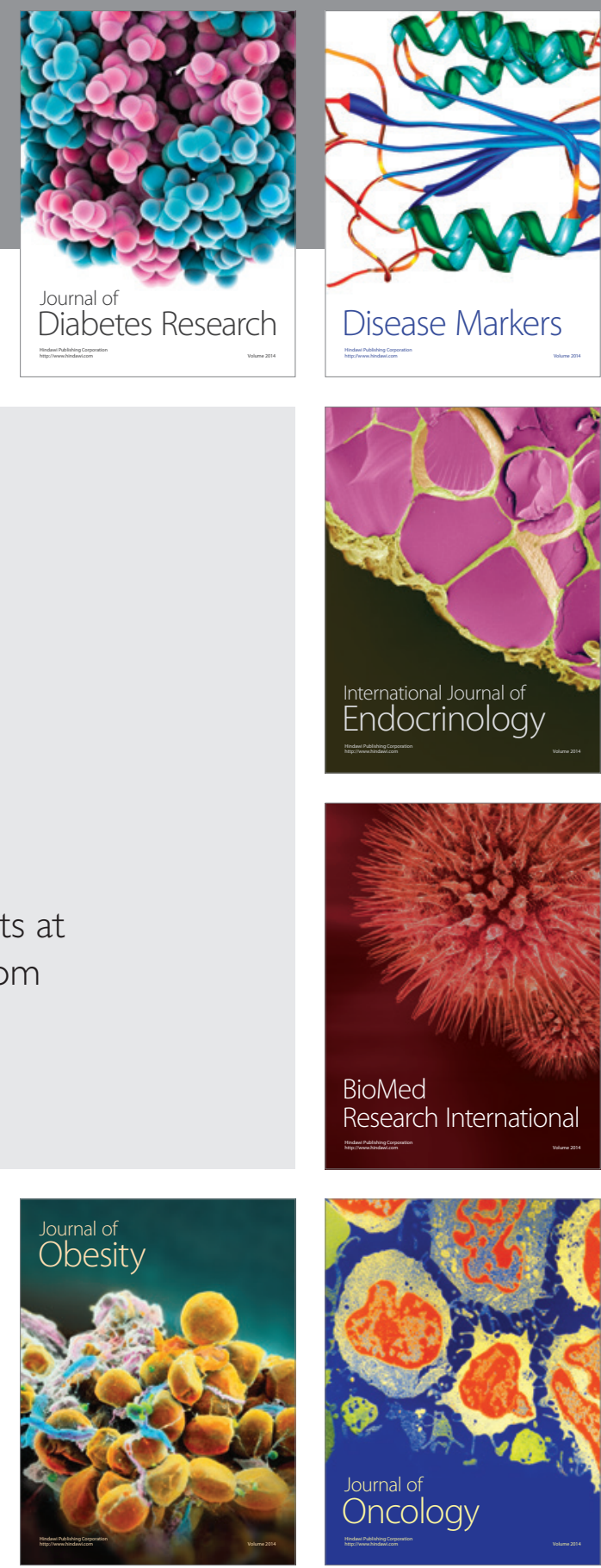

Disease Markers
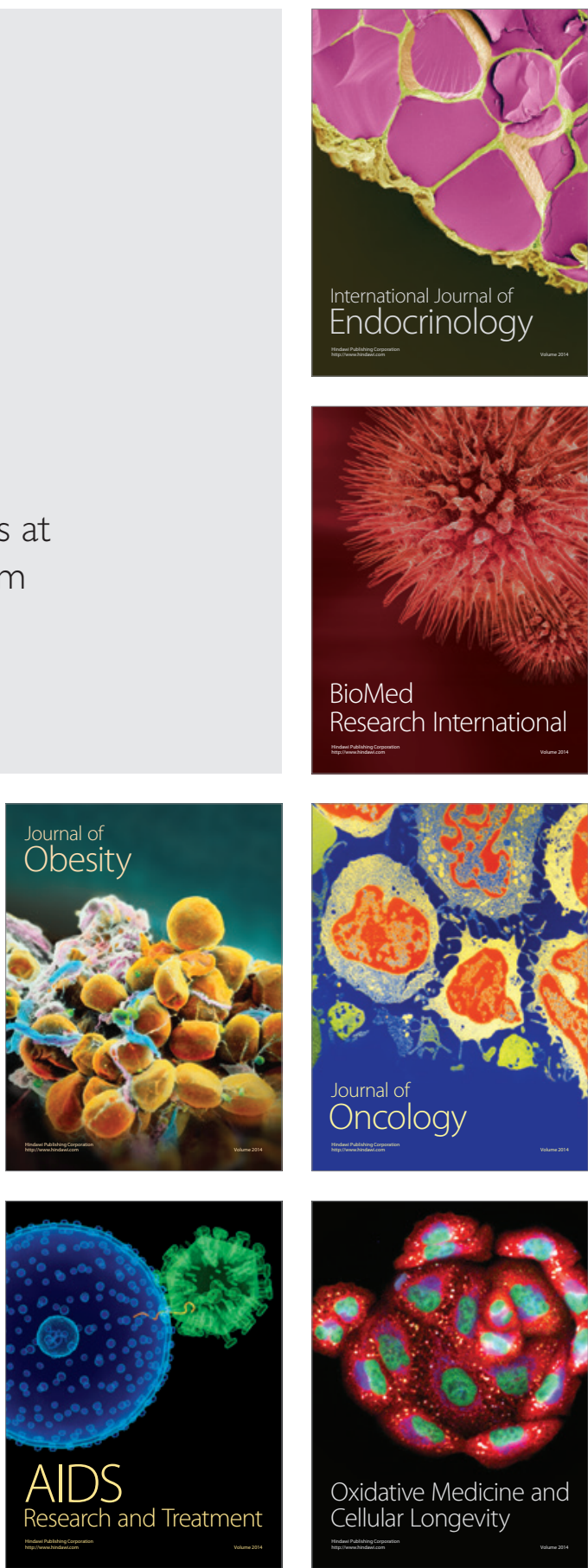